\title{
Producción de etanol empleando Panicum maximum pretratado: efecto de altas concentraciones de sólidos en la hidrólisis enzimática y fermentación de hidrólizados
}

\author{
Ethanol production using pretreated biomass of Panicum maximum: \\ effect of high solids loading on enzymatic hydrolysis \\ and fermentation of hydrolyzates \\ Carlos Castillo-Saldarriaga ${ }^{1 *} \quad$ Mario Velásquez-Lozano ${ }^{1}$ \\ Recibido 31 de julio de 2017, aceptado 3 de abril de 2018 \\ Received: July 31, 2017 Accepted: April 3, 2018
}

\begin{abstract}
RESUMEN
A pesar del incremento de estudios sobre la producción de etanol empleando biomasa lignocelulósica, el proceso aún presenta inconvenientes debido a los costos asociados a las etapas de transformación de la biomasa, como lo es la hidrólisis enzimática. Una de las soluciones para reducir estos costos, consiste en emplear altas concentraciones de sólidos y dosis mínimas de enzimas en función de la biomasa a hidrolizar. Por lo anterior, en el presente estudio se determinó el efecto del empleo de una alta concentración de sólidos sobre el rendimiento de la hidrólisis enzimática junto con las posibles implicaciones en una fermentación teniendo en cuenta la detoxificación de hidrolizados, empleando la biomasa lignocelulósica de Panicum maximum pretratado. Inicialmente se seleccionó la dosis de enzimas más adecuada para hidrolizar la biomasa pretratada con una posterior evaluación de un sistema lote alimentado de biomasa pretratada-enzimas. Para finalizar, se evaluaron dos métodos de detoxificación de hidrolizados, hidróxido de sodio $(\mathrm{NaOH})$ y carbón activado, determinando la reducción de la concentración de azúcares totales (ART) y evaluando el uso potencial del hidrolizado detoxificado como fuente de carbono para una fermentación alcohólica. La dosis recomendada para la hidrólisis enzimática fue de 61,44 BHU/g para el complejo de celulasas y $1,77 \mathrm{CBU} / \mathrm{g}$ para $\beta$-glucosidasas con una concentración final de azúcares reductores de 66,79 g/L en 48 h y una concentración de biomasa pretratada de 20\%p/p. Además, el hidrolizado detoxificado con $\mathrm{NaOH}$ presentó la mayor concentración de etanol y productividad con un valor de $19,43 \mathrm{~g} / \mathrm{L}$ y $0,81 \mathrm{~g} / \mathrm{L} / \mathrm{h}$, respectivamente.
\end{abstract}

Palabras clave: Alta concentración de sólidos, detoxificación, fermentación, hidrólisis enzimática.

\section{ABSTRACT}

Despite the increasing number of studies on the production of ethanol using lignocellulosic biomass, the process still has inconveniences due to the high costs associated with the biomass transformation steps, such as enzymatic hydrolysis. One of the solutions to reduce them, consist of using a high solids loading and a minimal enzyme doses in function of the pretreated biomass to hydrolyze. Due to the above, the present study determined the effect of high solids loading on the enzymatic hydrolysis yield and the possible

1 Departamento de Ingeniería Química y Ambiental. Universidad Nacional de Colombia, Sede Bogotá. Carrera 30 \#45-03. Bogotá, Colombia.E-mail: crcastillo@agrosavia.co; crcastillos@unal.edu.co; mevelasquez@unal.edu.co

* Autor de correspondencia 
implications on a fermentation considering the detoxification of the hydrolyzates. Pretreated biomass of Panicum maximum was used as a hydrolysis substrate. Initially, the adequate enzyme doses to hydrolyze the pretreated biomass was selected with a subsequence evaluation of a fed-batch system dosing pretreated biomass and enzymes. Finally, two detoxification methods were evaluated, overliming (NaOH) and activated carbon, to determine the effect on the concentration of total sugars (AR) and the potential use of the detoxified hydrolyzate as a carbon source for an alcoholic fermentation. The recommended doses for the enzymatic hydrolysis was $61.44 \mathrm{BHU} / \mathrm{g}$ of cellulases complex and $1.77 \mathrm{CBU} / \mathrm{g}$ of $\beta$-glucosidases with a final total sugars concentration of $66.79 \mathrm{~g} / \mathrm{L}$ after $48 \mathrm{~h}$ and a pretreated biomass concentration of $20 \% \mathrm{w} / \mathrm{w}$. Also, the detoxified hydrolyzate with overliming had the highest ethanol concentration and productivity with a value of $19.43 \mathrm{~g} / \mathrm{L}$ and $0.81 \mathrm{~g} / \mathrm{L} / \mathrm{h}$, respectively.

Keywords: High solid loading, detoxification, fermentation, enzymatic hydrolysis.

\section{INTRODUCCIÓN}

La alta variabilidad de los precios del barril de petróleo, gracias a la sobreoferta causada en gran parte por los países miembros de la OPEP (Organización de Países Exportadores de Petróleo, por sus siglas en ingles), ha generado problemas presupuestales en países que: (1) son dependientes de su producción para su sostenimiento o (2) utilizan los ingresos del sector para suplir gran parte de su PIB (Producto Interno Bruto) [1]. En Latinoamérica, países como México, Brasil, Colombia y Venezuela, han sido perjudicados en esta guerra de precios [2]. Por lo tanto, además de reducir el impacto negativo de los combustibles tradicionales, el etanol se ha convertido en una herramienta necesaria de desarrollar a gran escala para lograr una independencia económica de las fuentes tradicionales como el petróleo e inclusive el gas natural [3]. Tradicionalmente, el etanol se produce empleando como sustrato, el jugo de caña de azúcar y maíz. Sin embargo, ante el nuevo escenario mundial, el uso de estas materias primas está en desuso por razones ampliamente conocidas: (1) el precio ha venido en aumento debido a la demanda que tienen los productores por la necesidad de su uso para la producción de biocombustibles, (2) variabilidad climática que afecta la productividad de los cultivos, generando problemas éticos sobre el empleo de fuentes para la alimentación humana como materia prima para la producción de energía, lo cual se traduce en riesgos en la seguridad alimentaria y (3) estas materias primas requieren sistemas de producción extensivos, ocasionando el desplazamiento de otros cultivos a zonas con suelos improductivos o inclusive deforestación descontrolada para poder incrementar el área sembrada.
Por lo anterior, se han propuesto diferentes residuos agroindustriales como reemplazo de las materias primas convencionales, no obstante, estos ya son utilizados como materia prima para diferentes cadenas productivas como producción de biogás, compostaje, alimentación animal, entre otras, por lo que desarrollar una tecnología alrededor de estas, desplazaría la problemática a otro sector económico. Por esta razón, entre las nuevas alternativas para ser usadas como materia prima se encuentran los pastos perennes como el Panicum maximum (pasto guinea), gracias a su resistencia a largos períodos de sequía y radiación solar, gran sistema radicular, adaptabilidad a un amplio rango de altitudes, y una producción de biomasa seca entre 60 y 100 ton/ ha/año [4]. Esto lo convierte en una gran opción al poder cultivarse en suelos poco enriquecidos o zonas climáticas agrestes.

A pesar de lo anterior, la materia prima no es el único problema para la producción de etanol de segunda generación, su alto costo en operaciones de transformación como la hidrólisis enzimática y la fermentación, también reducen la posibilidad de su producción a gran escala. Entre las estrategias para reducir los costos asociados a estas etapas de proceso se ha propuesto el empleo de altas concentraciones de sólidos (ACS) en la hidrólisis enzimática de biomasa pretratada, toda vez que en esta etapa se debe garantizar una alta concentración de azúcares fermentables (ART) con el objetivo de lograr concentraciones de etanol elevadas que reduzcan el impacto económico de la destilación sobre el proceso. Por ejemplo, si al finalizar la fermentación, la concentración de etanol se encuentra por encima de $4 \% \mathrm{v} / \mathrm{v}$, la destilación puede alcanzar su margen inferior de factibilidad. Para 
lograr estos valores, la concentración de azúcares debe ser de al menos $8 \%$ p/v, lo que equivale a emplear una concentración igual o superior al $20 \%$ p/p de sólidos en la hidrólisis enzimática [5]. Lo anterior no es tan fácil, debido a que emplear ACS, trae consigo problemas durante su implementación. La falta de agua disponible en el sistema de hidrólisis reduce la transferencia de masa e incrementa el consumo de energía en el mezclado, además, aumenta el tiempo de hidrólisis y puede causar problemas de inhibición por producto o adsorción y/o desactivación de enzimas [6]. Por lo tanto, para usar ACS en la hidrólisis enzimática, se plantean diferentes estrategias de alimentación de sustrato pretratado, enzimas o ambos [7-9]. La hidrólisis pasa de ser, una operación por lotes a lote alimentado, donde el tiempo de dosificación se convierte en un factor determinante de su rendimiento. Distintos autores evaluaron el desempeño de una hidrólisis enzimática empleando como estrategia la dosificación simultanea de enzimas junto con biomasa hasta alcanzar una concentración de biomasa pretratada del $15 \%$ p/p y $30 \%$ p/p, obteniendo rendimientos de liberación de azúcares del $70.6 \%$ [10] y $80 \%$ [11], respectivamente.

Asimismo, el empleo de ACS en la hidrólisis también incrementa la probabilidad de liberar compuestos presentes en la biomasa pretratada como ácidos carboxílicos, ácido acético, furfural e hidroximetilfurfural (HMF), identificados como inhibidores de la fermentación [12]. Con el objetivo de reducir su impacto, se han desarrollado operaciones de detoxificación empleando métodos físicos, químicos y biológicos para reducir la concentración de los inhibidores y facilitar la fermentación del hidrolizado [13]. El más simple de estos métodos se basa en el lavado de la biomasa pretratada con agua, sin embargo, este lavado solo remueve una fracción de los inhibidores, dejando un remanente importante en la biomasa que es liberado en las operaciones subsecuentes [14-15]. Por lo tanto, el presente trabajo evaluó el efecto del empleo de una ACS de biomasa pretratada de $P$. maximum sobre el desempeño de una hidrólisis enzimática tipo lote alimentado suministrando una relación de dosis mínima de enzimas (complejo de celulasas y $\beta$-glucosidasas), determinando parámetros de proceso como rendimiento y productividad, con una posterior evaluación del uso potencial del hidrolizado como sustrato para una fermentación alcohólica evaluando dos métodos de detoxificación, carbón activado e hidróxido de sodio (overliming en inglés).

\section{MATERIALES Y MÉTODOS}

Biomasa lignocelulósica pretratada. La biomasa lignocelulósica empleada fue pasto Guinea (Panicum maximum) con un tiempo de corte de 5 meses y una composición de $0,284 \mathrm{~g}$ celulosa/g biomasa, $0,193 \mathrm{~g}$ hemicelulosa/g biomasa y $0,25 \mathrm{~g}$ lignina total/g biomasa. El pasto se procesó en una picadora hasta reducir el tamaño de los tallos a $5 \pm 0,76 \mathrm{~cm}$ y se colocó en una estufa de secado a $60 \pm 2{ }^{\circ} \mathrm{C}$ por $48 \mathrm{~h}$ para disminuir la humedad y evitar su deterioro. Posteriormente, se realizó una nueva reducción de tamaño hasta $2 \mathrm{~mm}$ empleando un molino de cuchillas. El pretratamiento se realizó con ácido sulfúrico diluido (1120801000, Emsure ${ }^{\circledR}$, Merck, Darmstadt, Alemania) a una concentración de $1,5 \%$ p/v y una concentración de sólidos de $12 \% \mathrm{p} / \mathrm{p}$ en recipientes tipo tapa rosca Boeco ${ }^{\circledR}$ a unas condiciones de $130^{\circ} \mathrm{C}, 15 \mathrm{psi}$ y $60 \mathrm{~min}$. Estas condiciones fueron seleccionadas teniendo en cuenta 4 criterios de decisión: recuperación de sólidos, digestibilidad de la biomasa pretratada, y rendimiento de celulosa y hemicelulosa de la prueba de digestibilidad; de acuerdo con los resultados obtenidos por Castillo-Saldarriaga [16]. Luego del pretratamiento, se realizó una filtración al vacío recuperándose la fracción sólida llamada biomasa pretratada, la cual se lavó en su totalidad con 100 $\mathrm{mL}$ agua destilada, con una relación sólido $(\mathrm{g})$ : líquido $(\mathrm{mL})$ de 1:10; y se colocó en una estufa de secado a $45 \pm 1^{\circ} \mathrm{C}$ hasta peso constante. $\mathrm{La}$ composición de la biomasa pretratada fue de $0,271 \mathrm{~g}$ celulosa/g biomasa pretratada y $0,070 \mathrm{~g}$ hemicelulosa/g biomasa pretratada. La biomasa se almacenó a una temperatura de $20 \pm 5^{\circ} \mathrm{C}$ hasta su uso. La determinación de celulosa, hemicelulosa y lignina, en la biomasa lignocelulósica sin pretratar y pretratada se realizó siguiendo los protocolos de caracterización estandarizados por Sluiter y colaboradores [17].

\section{Hidrólisis enzimática con alta concentración} de sólidos (ACS). La evaluación del efecto de la ACS sobre la hidrólisis enzimática del $P$. maximum pretratado se realizó en dos etapas. En la primera se determinó la concentración mínima de enzimas del complejo de celulasas (NS22086) 
y $\beta$-glucosidasas (NS22118) para una hidrólisis enzimática con una concentración de sólidos $5 \%$ p/p de biomasa pretarada. La segunda parte consistió en la evaluación de una estrategia de dosificación de biomasa pretratada-enzima para lograr una hidrólisis enzimática con ACS que garantice una concentración de azúcares elevada en el hidrolizado. Teniendo en cuenta que este será empleado como sustrato en un proceso de fermentación para la producción de etanol, la concentración de azúcares fermentables debía ser lo más elevada posible logrando incrementar la concentración de etanol al final de la fermentación, a mayor etanol presente en el hidrolizado fermentado, los costos de las operaciones de separación se reducen.

Concentración mínima de enzimas. Las enzimas utilizadas fueron: un complejo de celulasas (NS22086; Lot \# VCPI0006) y $\beta$-glucosidasas (NS22118; Lot \# DCN00218) donadas por la empresa Novozymes A/S (Dinamarca). Las enzimas presentaron una concentración de 1.000 unidades de hidrólisis de biomasa (BHU)/g de mezcla y 250 unidades de celobiosa (CBU)/g de mezcla, respectivamente. El límite inferior de la concentración para las celulasas fue el indicado en la ficha técnica de la enzima $(1,30$ BHU/g). Para la $\beta$-glucosidasa, el límite inferior fue cero $(0 \mathrm{CBU} / \mathrm{g})$, considerando que los complejos comerciales de celulasas tienen una concentración limitante de esta enzima en su composición. Por otro lado, el límite superior fue establecido en base a la ficha técnica (1.77 CBU/g). La dosis de enzima se estableció en función de la cantidad de biomasa pretratada. La matriz experimental se obtuvo bajo los criterios de un diseño central compuesto con 2 réplicas del punto central, para un total de 11 experimentos (Tabla 1 ).

Como blanco se realizó un tratamiento con solución tampón y biomasa pretratada sin adición de enzimas. Esta evaluación se llevó a cabo en recipientes de $50 \mathrm{~mL}$ tapa rosca Boeco®. Las condiciones del ensayo fueron: $50^{\circ} \mathrm{C}$ y agitación magnética durante $48 \mathrm{~h}$, empleando una solución tampón de citrato de sodio $50 \mathrm{mM}$ a pH 4,8. La concentración inicial de sólidos de la hidrólisis enzimática se ajustó dosificando solución tampón y biomasa pretratada por gravimetría respecto a una base total de $40 \mathrm{~g}$ (solución tampón + biomasa pretratada) y manteniéndose constante durante todo el proceso. Con el fin de evitar contaminación bacteriana se
Tabla 1. Diseño experimental para la determinación de la dosis de enzimas mínima en la hidrólisis enzimática.

\begin{tabular}{|c|c|c|}
\hline Exp. & $\begin{array}{c}\text { Complejo celulasas } \\
(\mathbf{B H U} / \mathbf{g}) *\end{array}$ & $\begin{array}{c}\beta \text {-glucosidasa } \\
\text { (CBU/g)* }\end{array}$ \\
\hline $\mathrm{B}^{+}$ & - & - \\
\hline 1 & 61,44 & 1,77 \\
\hline 2 & 61,44 & 0,00 \\
\hline 3 & 31,37 & 0,89 \\
\hline 4 & 1,30 & 1,77 \\
\hline 5 & 31,37 & 0,00 \\
\hline 6 & 31,37 & 1,77 \\
\hline 7 & 1,30 & 0,89 \\
\hline 8 & 61,44 & 0,89 \\
\hline 9 & 31,37 & 0,89 \\
\hline 10 & 1,30 & 0,00 \\
\hline 11 & 31,37 & 0,89 \\
\hline
\end{tabular}

* Las concentraciones enzimáticas están expresadas en términos de unidades enzimáticas/g de biomasa pretratada.

+ En el blanco no se adicionaron enzimas.

adicionó tetraciclina a una concentración de $10 \mu \mathrm{g} /$ $\mathrm{mL}$. A las 24 y 48 h de hidrólisis, se determinó la concentración de azúcares reductores totales (ART) por el método colorimétrico DNS [16], cuya eficacia como alternativa de cuantificación de azúcares en una hidrólisis enzimática ha sido demostrada por otros autores [18-20]. El software Design-Expert ${ }^{\circledR}$ versión 7, fue utilizado para la generación y análisis de varianza (ANOVA) del diseño experimental. A su vez, se generó un modelo cuadrático para la variable de respuesta.

Para determinar cuál fue la mejor dosis de enzima, se calculó el rendimiento de conversión de celulosa a glucosa $\left(\mathrm{Y}_{\mathrm{Cel}}\right)$ en cada uno de los ensayos de hidrólisis enzimática. De esta manera se tendría certeza de cual dosis es la adecuada para degradar más celulosa presente en la biomasa pretratada de P. maximum bajo las condiciones de pretratamiento empleadas en este trabajo. El cálculo del rendimiento de conversión se realizó mediante la ecuación (1):

$$
Y_{\text {Cel }}=\frac{[\text { Glucosa }]}{1,111 \times f[\text { Biomasa }]}
$$

Hidrólisis enzimática por lote alimentado. El objetivo de emplear una hidrólisis enzimática tipo lote alimentado es lograr una alta concentración de sólidos 
en el medio para conseguir una concentración de azúcares elevada. Como se observa en la Figura 1, los ensayos iniciaron con una concentración de biomasa pretratada de $5 \% \mathrm{p} / \mathrm{p}$, realizando dosificaciones de biomasa pretratada y enzimas a las 6,12 y $24 \mathrm{~h}$ hasta alcanzar concentraciones de sólidos del 7,9, $10,12,15$ y $20 \%$ p/p. El tiempo total de hidrólisis enzimática fue de $48 \mathrm{~h}$.

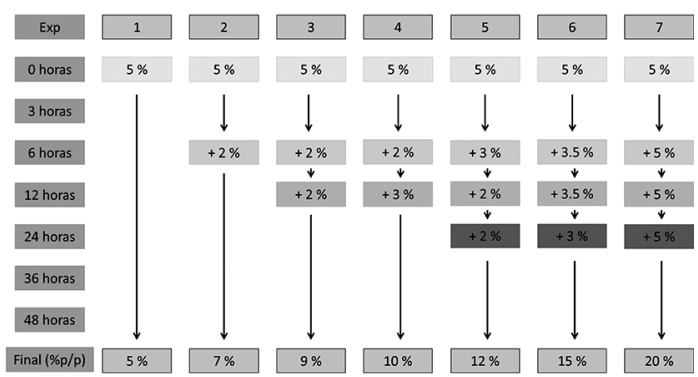

Figura 1. Dosificación de biomasa pretratada en la hidrólisis enzimática tipo lote alimentado.

La selección de los tiempos de dosificación y tiempo total se realizaron en base a datos obtenidos de ensayos preliminares de hidrólisis enzimática con una concentración de sólidos de $5 \%$ p/p (información no presentada). El tiempo final de hidrólisis de estos ensayos preliminares fue de $144 \mathrm{~h}$ realizando muestreos cada $24 \mathrm{~h}$. En estos ensayos se observó que después de $48 \mathrm{~h}$ de hidrólisis enzimática la concentración de ART no se incrementó de forma significativa, pasando de $15,11 \mathrm{~g} / \mathrm{L}$ a $16,98 \mathrm{~g} / \mathrm{L}(\mathrm{t}=144 \mathrm{~h})$, por esta razón el tiempo final de hidrólisis se fijó en $48 \mathrm{~h}$. Los tiempos de dosificación se establecieron antes de las 24 h, por la rápida degradación de la biomasa pretratada al inicio de la hidrólisis, al encontrarse en el medio una concentración de $11,35 \mathrm{~g} / \mathrm{L}$ de ART a las 24 h de proceso. La dosis de biomasa pretratada en cada tiempo de dosificación se estableció respecto a lo reportado por otros autores tratando de dejar tiempos prudentes para la degradación de celulosa presente en la biomasa pretratada [21-25]. La dosis de enzima se estableció respecto a la cantidad de biomasa pretratada suministrada en cada dosificación. La solución tampón, $\mathrm{pH}$, agitación, temperatura fue la misma de la sección anterior. Cada experimento se realizó por triplicado y la concentración de azúcares reductores totales se determinó por el método de DNS.
Detoxificación y fermentación. El hidrolizado obtenido con las mejores condiciones de dosis de enzimas y biomasa pretratada, se empleó para evaluar las dos últimas etapas de la producción de etanol a partir de biomasa lignocelulósica, detoxificación del hidrolizado y fermentación. En la etapa de detoxificación se emplearon dos tratamientos: hidróxido de sodio y carbón activado usando unas condiciones de proceso previamente establecidas por otros autores [26-29]. En la fermentación se utilizó la levadura Saccharomyces cerevisiae como microorganismo de referencia, determinando luego de $24 \mathrm{~h}$, concentración de etanol, rendimiento y productividad.

Método de detoxificación. Para la detoxificación de los hidrolizados se emplearon tres tratamientos: detoxificación con hidróxido de sodio, carbón activado y una combinación de ambos. Cada uno de los métodos de detoxificación se aplicó sobre $150 \mathrm{~mL}$ de hidrolizado.

Detoxificación con Hidróxido de Sodio. El pH del hidrolizado se ajustó a un valor de 12 unidades de $\mathrm{pH}$ empleando perlas de hidróxido de sodio (1064691000, Emsure ${ }^{\circledR}$, Merck, Darmstadt, Alemania). La cantidad de perlas dependerá del $\mathrm{pH}$ de la solución tampón empleada para la hidrólisis enzimática. Las condiciones de la detoxificación fueron de $60^{\circ} \mathrm{C}$ a $150 \mathrm{rpm}$ por $1 \mathrm{~h}$ [26-27].

Detoxificación con Carbón Activado. El hidrolizado se mezcló con 3,75 g de carbón activado (1025141000, Merck, Darmstadt, Alemania), 2,5\%p/p, a una

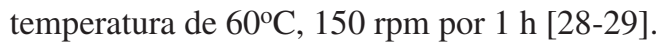

Combinación de Métodos. Primero se realizó una detoxificación con carbón activado seguida del tratamiento con hidróxido de sodio [26].

Luego de la detoxificación, cada hidrolizado fue centrifugado a $15000 \mathrm{rpm}$ por un tiempo de $10 \mathrm{~min}$. El sobrenadante se filtró al vacío empleando una membrana de nitrato de celulosa de $0,45 \mu \mathrm{m}$. Todo esto para retirar sólidos suspendidos y disminuir interferencias en la fermentación.

Fermentación de hidrolizados. La levadura empleada para los ensayos de fermentación fue Saccharomyces cerevisiae Ethanol Red ${ }^{\circledR}$ (Lesaffre, Marcq-en-Baroeul, France). La levadura se mantuvo 
en una solución de glicerol al 30\%p/v en un criocongelador a $-70 \pm 0,1^{\circ} \mathrm{C}$. Para los ensayos, la activación de la levadura se realizó en medio líquido extracto de levadura y malta $(\mathrm{YM})$ a $30 \pm 0,5^{\circ} \mathrm{C}$ por $24 \mathrm{~h}$. Luego se realizó un cultivo en medio PDA a $30 \pm 0,5^{\circ} \mathrm{C}$. Después de $48 \mathrm{~h}$ de crecimiento, se incubó en un recipiente tipo Erlenmeyer de $250 \mathrm{~mL}$ con un volumen de trabajo de $50 \mathrm{~mL}$ de medio YM modificado estéril $(50 \mathrm{~g} / \mathrm{L}$ glucosa, $5 \mathrm{~g} / \mathrm{L}$ peptona, $3 \mathrm{~g} / \mathrm{L}$ extracto de levadura, $3 \mathrm{~g} / \mathrm{L}$ extracto de malta, $1 \mathrm{~g} / \mathrm{L}$ de cloruro de amonio, $0,4 \mathrm{~g} / \mathrm{L}$ fosfato ácido de potasio) a $30 \pm 0,5^{\circ} \mathrm{C}$ por $24 \mathrm{~h}$. El cultivo fue centrifugado en un recipiente estéril a $10.000 \mathrm{rpm}$ por $10 \mathrm{~min}$. Las células de levadura fueron resuspendidas en solución salina $0,85 \%$ p/v ajustando la población celular a un valor aproximado de $1 \times 10^{9}$ células $/ \mathrm{mL}$ por recuento en cámara de Neubauer.

A cada uno de los hidrolizados detoxificados se le ajustó el $\mathrm{pH}$ a un valor de 5 empleando hidróxido de sodio o ácido sulfúrico según fuese el caso. El volumen de fermentación fue de $50 \mathrm{~mL}$ de hidrolizado suplementado con 0,33 g de Yeast Nitrogen Base YNB (51483, Sigma-Aldrich, St. Louis, MO) [30]. Cada hidrolizado suplementado se inoculó con $10 \% \mathrm{v} / \mathrm{v}$ garantizando una concentración inicial de células de $1 \times 10^{7}$ células $/ \mathrm{mL}$. La fermentación se llevó a cabo a una temperatura de $30 \pm 1^{\circ} \mathrm{C}$, con agitación magnética por $24 \mathrm{~h}$. Con el fin de garantizar condiciones anaerobias se usaron recipientes tipo tapa rosca Boeco ${ }^{\circledR}$ de $50 \mathrm{~mL}$, acoplando un sistema de air-locks. Este accesorio permite la salida de dióxido de carbono, subproducto de la fermentación evitando la entrada de oxígeno, de esta manera se garantiza la formación de una atmosfera anaeróbica al interior del sistema experimental. La cuantificación de glucosa, etanol y glicerol se realizó por HPLC. Se empleó una columna Bio-Rad Aminex HPX-87H (Bio-Rad Philadelphia, PA, USA). El equipo utilizado fue un cromatografo Dionex (Thermo Scientific, Waltham, MA) con un detector de índice de refracción, RI-101 a una temperatura de $40^{\circ} \mathrm{C}$ (Shodex New York, NY, USA). Como fase móvil se usó una solución de ácido sulfúrico $5 \mathrm{mM}$ desionizada y desgasificada con un flujo de $0.6 \mathrm{~mL} / \mathrm{min}$. El volumen de inyección fue $20 \mu \mathrm{L}$. La temperatura del horno fue de $65^{\circ} \mathrm{C}$. La concentración final de biomasa se determinó por peso seco. Como parámetros del proceso de fermentación se determinó: (1) el rendimiento de biomasa/sustrato $\left(\mathrm{Y}_{\mathrm{X}}\right)$ y (2) el rendimiento etanol/ sustrato $\left(\mathrm{Y}_{\mathrm{p}}\right)$, expresados como la relación existente, entre la cantidad de biomasa final o la cantidad de etanol final, según sea el caso, respecto al sustrato consumido. La variable sustrato consumido se calculó con base a la cantidad de glucosa al inicio y al final de la fermentación. Por otro lado, (3) la productividad del etanol se expresó como la cantidad de etanol respecto a una unidad de volumen y tiempo. Todos los parámetros antes mencionados se calcularon a las 24 horas de fermentación.

\section{RESULTADOS Y ANÁLISIS}

Dosis de enzimas. A continuación, se encuentran los resultados de la evaluación de diferentes dosis de enzimas:

Tabla 2. Concentración de azúcares reductores (g/L) a las 24 y $48 \mathrm{~h}$ junto con el rendimiento de celulosa.

\begin{tabular}{|r|c|c|c|}
\hline Exp.* $^{*}$ & AR-24 h $(\mathbf{g} / \mathbf{L})$ & AR-48 h $(\mathbf{g} / \mathbf{L})$ & $\mathbf{Y}_{\mathbf{C e l}}$ \\
\hline B & - & - & - \\
\hline 1 & $20,1 \pm 1,0$ & $22,0 \pm 1,1$ & 0,80 \\
\hline 2 & $17,9 \pm 0,9$ & $20,0 \pm 1,0$ & 0,73 \\
\hline 3 & $16,1 \pm 0,8$ & $18,8 \pm 0,9$ & 0,69 \\
\hline 4 & $7,2 \pm 0,4$ & $8,0 \pm 0,3$ & 0,29 \\
\hline 5 & $15,4 \pm 0,8$ & $16,6 \pm 0,6$ & 0,61 \\
\hline 6 & $15,7 \pm 0,7$ & $16,7 \pm 0,8$ & 0,61 \\
\hline 7 & $6,8 \pm 0,2$ & $7,2 \pm 0,4$ & 0,26 \\
\hline 8 & $20,3 \pm 1,2$ & $21,7 \pm 0,9$ & 0,79 \\
\hline 9 & $15,2 \pm 0,6$ & $16,4 \pm 0,9$ & 0,60 \\
\hline 10 & $5,4 \pm 0,1$ & $6,9 \pm 0,5$ & 0,22 \\
\hline 11 & $15,6 \pm 0,8$ & $17,9 \pm 1,0$ & 0,65 \\
\hline
\end{tabular}

*La dosis de enzima para cada experimento se puede observar en la Tabla 1.

Para el rendimiento de celulosa se desarrolló el siguiente modelo cuadrático a partir de los datos obtenidos (ecuación 2):

$$
\begin{gathered}
Y_{C e l}=0,20+0,0162 \times C C+0,0834 \times \\
B-0,0001 \times C C^{2}-0,0322 \times B^{2}
\end{gathered}
$$

Donde, CC es la concentración del complejo de celulasas (BHU/g) y B es la concentración de $\beta$-glucosidasas (CBU/g). No existió una interacción estadística entre las variables evaluadas. El valor F del modelo fue de 72,21, lo que implica que es significativo y solo existe $0,01 \%$ de probabilidad de alteración por ruido. La falta de ajuste del modelo fue no significativa, con valor $\mathrm{F}$ de 0,34 
y un valor $\mathrm{P}$ de 0,8047 , por lo tanto, el modelo puede usarse para predecir el comportamiento del rendimiento de celulosa en la hidrólisis enzimática con las diferentes dosis de enzimas evaluadas. Para el modelo del rendimiento de celulosa el valor de precisión adecuada fue de 21,859, lo cual indica que el modelo presenta una señal adecuada para reproducir los resultados experimentales. El valor del coeficiente de determinación $\left(\mathrm{R}^{2}\right)$ fue de 0,9863 a $95 \%$ de confianza, garantizando el ajuste del modelo. El modelo cuadrático obtenido puede explicar el 98,63\% de la variabilidad de la respuesta y el $1,37 \%$ de la variación total no se le puede atribuir a las variables estudiadas. El coeficiente de determinación previsto, $\mathrm{R}^{2}, 0,9727$, del análisis de varianza se encontró en concordancia coeficiente de terminación ajustado $\mathrm{R}^{2}, 0,9371$.

Como se observa en la Figura 2, la dosis de complejo de celulasas tiene un efecto significativo (valor P: $<0,0001$ ) sobre el rendimiento de celulosa, mientras que la dosis de $\beta$-glucosidasas (valor P: 0,1635) no tiene ningún efecto sobre esta variable.

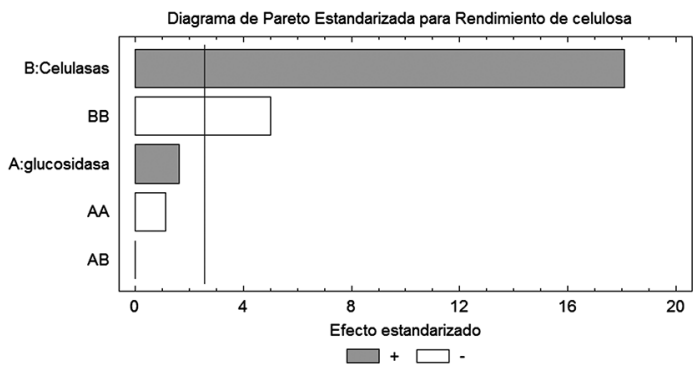

Figura 2. Diagrama de Pareto estandarizado para la concentración de azúcares reductores. A: concentración de $\beta$-glucosidasas (CBU/g), B: concentración del complejo de celulasas (BHU/g) y AB: interacción de las variables experimentales.

Ferreira y colaboradores [31], evaluaron cuales eran las variables que mayor efecto tenían en la conversión de celulosa a glucosa durante una hidrólisis enzimática de dos plantas arbustivas, Cistus ladanifer y Cytisus striatus, sometidas previamente a un pretratamiento con ácido sulfúrico diluido, $2,6 \%$ p/p y una concentración de sólidos de $17 \%$ p/p durante 75 minutos a $150^{\circ} \mathrm{C}$. Las enzimas empleadas fueron un complejo de celulasas (NS50013) y $\beta$-glucosidasas (NS50010) suministradas por Novozymes. Del estudio se concluyó que la concentración de celulasas es la variable que mayor efecto tiene sobre la conversión de celulosa a glucosa en una hidrólisis enzimática con $72,27 \%$, mientras que la suplementación de $\beta$-glucosidasas solo tiene un efecto del $8,92 \%$ sobre el desempeño de la hidrólisis. Este resultado coincide con la tendencia observada en los ensayos realizados en el presente trabajo. El efecto no significativo de la $\beta$-glucosidasas también se evidencia en la Figura 3, al no observarse cambios en el rendimiento de celulosa con el incremento en la dosis de $\beta$-glucosidasas a una dosis de complejo de celulasas constante.

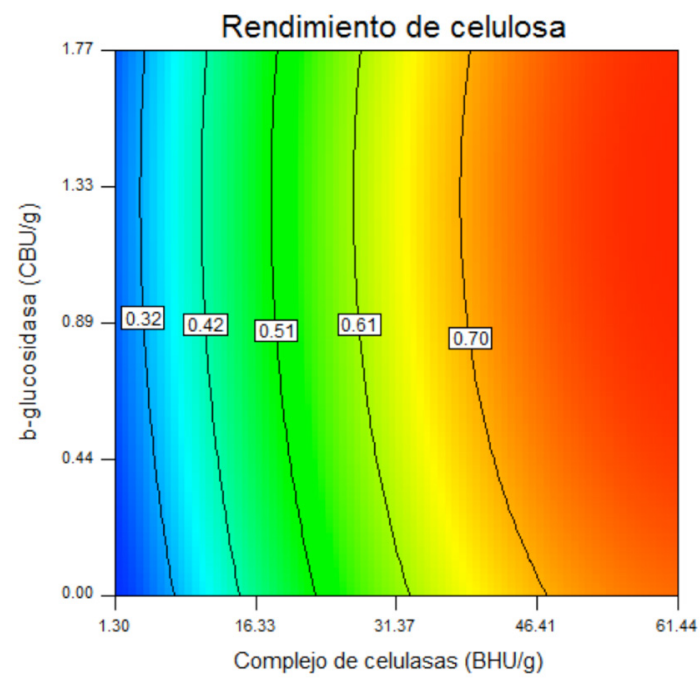

Figura 3. Contorno de superficie de respuesta para la concentración de azúcares reductores de acuerdo con el modelo (Condiciones de proceso: $50^{\circ} \mathrm{C}$; agitación magnética; 48 horas).

Luego de 24 h de hidrólisis enzimática, debido a la pérdida de efectividad de la suplementación de $\beta$-glucosidasas, el rendimiento de celulosa no aumentó. Este efecto se evidenció en todos los experimentos. Pallapolu y colaboradores [32], estudiaron el efecto de la concentración de celulasas y suplementación de $\beta$-glucosidasas en una hidrólisis enzimática con una concentración de sólidos $1 \% \mathrm{p} / \mathrm{v}$ de switchgrass variedad Dacotah pretratado con ácido sulfúrico diluido. En los ensayos se observó que durante la hidrólisis el efecto de la suplementación de $\beta$-glucosidasas sobre la conversión de celulosa 
a glucosa disminuyó luego de 24 h, siempre y cuando, no se realizará una nueva suplementación. Este fenómeno también fue observado por Kumar y Wyman [33], los cuales estudiaron la adsorción de celulasas y $\beta$-glucosidasas durante una hidrólisis enzimática de álamo pretratado con ácido sulfúrico diluido. Estos autores atribuyeron el descenso en la conversión a la adsorción causada por parte de la lignina residual en la biomasa pretratada sobre las enzimas empleadas, que para su caso en particular con álamo fue de 170,9 mg de enzima/g de sustrato pretratado y $301,3 \mathrm{mg}$ enzima/g sustrato pretratado, para el complejo de celulasas y $\beta$-glucosidasas, respectivamente.

Teniendo en cuenta lo anterior, el máximo rendimiento de celulosa de los ensayos de hidrólisis enzimática fue $0,80 \mathrm{~g}$ celulosa/g biomasa pretratada con una dosis del complejo de celulasas de 61,44 BHU/g biomasa pretratada seca y $\beta$-glucosidasas de 1,77 $\mathrm{CBU} / \mathrm{g}$ biomasa pretratada seca.

Hidrólisis enzimática tipo lote alimentado. Los resultados de los ensayos realizados se resumen en la siguiente tabla:

Tabla 3. Azúcares reductores totales (ART) y rendimiento de celulosa $\left(\mathrm{Y}_{\mathrm{Cel}}\right)$ de la hidrólisis enzimática a diferentes concentraciones de sólidos.

\begin{tabular}{|c|c|c|c|}
\hline $\begin{array}{c}\text { Conc. Sólidos } \\
(\mathbf{\%} / \mathbf{p})^{\mathbf{a}}\end{array}$ & $\begin{array}{c}\text { Biomasa } \\
\mathbf{( g )}^{\mathbf{b}}\end{array}$ & $\begin{array}{c}\text { ART } \\
(\mathbf{g} / \mathbf{L})\end{array}$ & $\mathbf{Y}_{\text {Cel }}$ \\
\hline 5 & 2 & $17,91 \pm 1,84$ & 0,65 \\
\hline 7 & 2,8 & $26,25 \pm 1,49$ & 0,69 \\
\hline 9 & 3,6 & $36,21 \pm 1,53$ & 0,74 \\
\hline 10 & 4 & $38,81 \pm 2,01$ & 0,71 \\
\hline 12 & 4,8 & $42,37 \pm 0,99$ & 0,65 \\
\hline 15 & 6 & $51,63 \pm 3,40$ & 0,63 \\
\hline 20 & 8 & $66,79 \pm 1,98$ & 0,61 \\
\hline
\end{tabular}

Condiciones de proceso: $50^{\circ} \mathrm{C}$, agitación magnética, 61.44 BHU/g complejo de celulasas y $1.77 \mathrm{CBU} / \mathrm{g}$

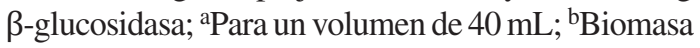
pretratada.

Cuando se realiza una hidrólisis enzimática con alta concentración de sólidos se pueden presentar problemas como: reducción en la transferencia de masa y calor, inhibición por productos derivados de la degradación de hemicelulosa y celulosa que quedan adsorbidos en la biomasa pretratada y son liberados por la degradación de la biomasa por parte de las enzimas, y adsorción de las enzimas por la biomasa pretratada. Todos estos problemas reducen el rendimiento de la hidrólisis. En el presente trabajo, los rendimientos obtenidos no presentaron valores mayores posiblemente por problemas de transferencia de masa asociados al sistema experimental manejado para los ensayos. Adicionalmente, luego de pretratar la biomasa con ácido diluido, queda una fracción de lignina presente en el material por la misma selectividad del ácido hacia la hemicelulosa. La acumulación de lignina pudo reducir la degradación de celulosa [34] y adsorber parte de la dosis de enzimas colocada durante la hidrólisis enzimática [33].

Como se observa en la Tabla 3, la concentración de azúcares reductores (AR) estuvo entre $18 \mathrm{~g} / \mathrm{L}$ y $67 \mathrm{~g} / \mathrm{L}$, con un incremento en la concentración de biomasa pretratada de $5 \% \mathrm{p} / \mathrm{p}$ a $20 \% \mathrm{p} / \mathrm{p}$. El rendimiento de celulosa, calculado con base en la concentración de azúcares reductores totales presentó un valor inferior de $0,61 \mathrm{~g}$ glucosa/g biomasa pretratada seca y superior de $0,74 \mathrm{~g}$ glucosa/g biomasa pretratada seca. Al haberse presentado rendimientos similares, se descartan problemas de inhibición durante la hidrólisis enzimática por suplementación de enzimas. Los diferentes ensayos de hidrólisis enzimática con alta concentración de sólidos alcanzaron a las $48 \mathrm{~h}$ un rendimiento similar a la hidrólisis con el límite inferior del ensayo (5\%p/p).

A continuación, se encuentran los perfiles de concentración de AR y rendimiento de celulosa en la hidrólisis enzimática con diferentes concentraciones de sólidos mediante la estrategia de lote alimentado (Ver Figura 4). La Figura 4 (A), relaciona la concentración de AR respecto al tiempo como función de la concentración de biomasa pretratada sometida a hidrólisis enzimática. En todas las concentraciones de sólido evaluadas, la concentración de AR presentó un comportamiento patrón con una alta tasa de liberación al inicio de la hidrólisis que luego disminuye con el transcurrir del tiempo.

Este comportamiento se debe a la presencia en la biomasa pretratada de celulosa debilitada estructuralmente, lo que incrementa la porosidad 

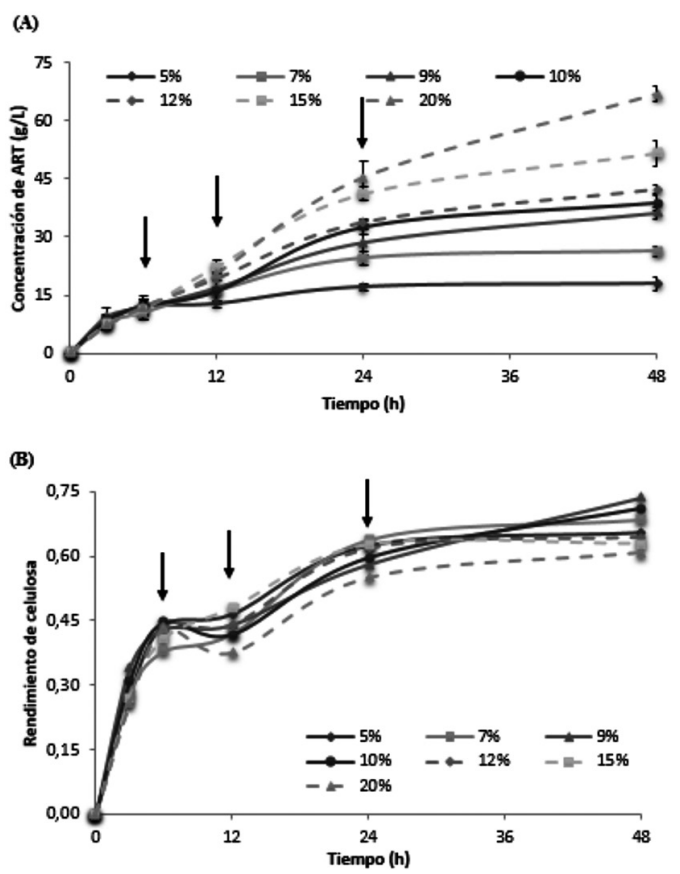

Figura 4. (A) Concentración de azúcares reductores totales (ART) respecto al tiempo, (B) Rendimiento de celulosa respecto al tiempo.

de la biomasa facilitando la accesibilidad de las enzimas sobre la celulosa más disponible y fácilmente digestible. Por ejemplo, en el perfil de 5\%p/p y $7 \% \mathrm{p} / \mathrm{p}$, la mayor variación de la concentración de AR se presentó en las primeras $24 \mathrm{~h}$ de hidrólisis. Sin embargo, concentraciones de sólidos más elevadas, $15 \%$ p/p y $20 \%$ p/p, continuaron liberando azúcares reductores sin alcanzar un límite superior en las 48 h de hidrólisis enzimática. Cuando la hidrólisis enzimática se realizó con una concentración de sólidos de 9\%p/p, 10\%p/p y 12\% p/p, la concentración de AR a las 48 h no presentó diferencias. A pesar de que las concentraciones finales de azúcares reductores a diferentes concentraciones de sólidos fueron diferentes, como se observa en la Figura 4 (B), el comportamiento del rendimiento de celulosa fue similar en todos los ensayos. Con un valor promedio de 0,67 $\pm 0,04 \mathrm{~g}$ de celulosa/g de biomasa pretratada, la estrategia de lote alimentado demostró que la biomasa tratada con el pretratamiento con ácido sulfúrico diluido tenía unas buenas condiciones para ser empleada en una hidrólisis enzimática con alta concentración de sólidos. Adicionalmente, la estrategia de lote alimentado aumentó el rendimiento de celulosa en comparación a los ensayos preliminares con una concentración inicial de sólidos de $20 \% \mathrm{p} / \mathrm{p}$, donde el rendimiento fue de $0,41 \mathrm{~g}$ glucosa/g biomasa pretratada, Para estos ensayos se realizó un procedimiento similar, solo que se realizó una única adición de enzimas y biomasa pretratada al inicio, es decir, 0 horas. Sin embargo, no se descarta que, al incrementar el tiempo de hidrólisis por encima de 48 horas, se pueda lograr un incremento en los rendimientos de cada uno de los ensayos.

Fermentación de hidrolizados. Los resultados promedio de los tratamientos de detoxificación se encuentran en la Figura 5.

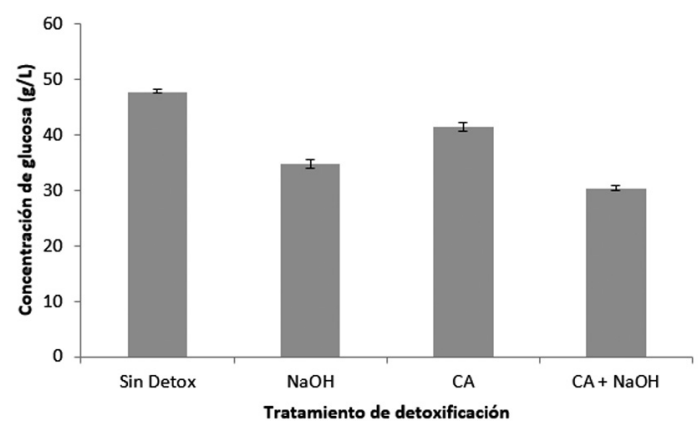

Figura 5. Concentración de glucosa en el hidrolizado luego de aplicar las diferentes estrategias de detoxificación.

El tratamiento de detoxificación que causó la mayor pérdida de glucosa fue la combinación de carbón activado e hidróxido de sodio con $36 \%$, y una concentración final de glucosa de $30,5 \mathrm{~g} / \mathrm{L}$. La detoxificación con hidróxido de sodio redujo a $35 \mathrm{~g} / \mathrm{L}$ (27\%) la concentración de glucosa, mientras que la detoxificación con carbón activado la redujo a 41,5 g/L (13\%). La pérdida de glucosa luego de un tratamiento de detoxificación aún no presenta resultados concluyentes en la literatura. Hodge y colaboradores [26], realizaron la detoxificación con bases como el hidróxido de sodio e hidróxido de calcio en un hidrolizado encontrando una pérdida de azúcares de $11 \%$, mientras que para el tratamiento con carbón activado no hubo pérdida de ninguno de los azúcares. Respecto a los inhibidores, reportaron para un tratamiento con hidróxido de calcio una remoción del $48 \%$ al $72 \%$ de HMF, mientras que para el carbón activado en todos los ensayos la remoción de HMF fue de superior al 85\%. No hubo 
remoción para el ácido fórmico, levulínico y acético [26]. Por otro lado, Millati y colaboradores [27], estudiaron el efecto de $\mathrm{pH}$, tiempo y temperatura del tratamiento de detoxificación básico en un hidrolizado de residuos forestales, logrando una remoción del $30 \%$ de hidroximetilfurfural (HMF) y fufural. Además, resaltaron una pérdida del $70 \%$ de azúcares en sus ensayos con hidróxido de calcio a pH 12, límite superior seleccionado para sus tratamientos de detoxificación. Otros autores también han reportado la remoción de inhibidores con estos tratamientos de detoxificación. Miyafuji y colaboradores, lograron remover el 100\% de HMF y furfural con carbón activado [28]. Rodrigues y colaboradores, también obtuvieron excelentes resultados con carbón activado, al remover entre un $90 \%$ y $98 \%$, los compuestos fenólicos presentes en un hidrolizado de bagazo de caña [29]. El tratamiento con hidróxido de sodio remueve componentes considerados inhibidores de la fermentación como furfural, HMF y ácido acético, junto con azúcares fermentables presentes en el hidrolizado. Larsson y colaboradores, evaluaron 15 tratamientos de detoxificación en un hidrolizado de astillas de abeto rojo (Picea abies) obtenido de un pretratamiento con ácido sulfúrico diluido a $0,5 \%$ p/p y $222^{\circ} \mathrm{C}$ durante 7 minutos. Entre los tratamientos de detoxificación se encontraban dos tratamientos básicos, hidróxido de sodio e hidróxido de calcio (overliming). Con ambos tratamientos, el hidrolizado se llevó a un pH 10 con un tiempo de residencia de $1 \mathrm{~h}$ y posterior filtración. La remoción de azúcares reductores fue de $1 \%$ en ambos tratamientos respecto al hidrolizado sin tratamiento. El rendimiento de etanol no presentó diferencias significativas. La productividad a las $6 \mathrm{~h}$ de fermentación fue mayor para el tratamiento con hidróxido de calcio con $1,21 \mathrm{~g} / \mathrm{L} / \mathrm{h}$ seguida del hidróxido de sodio con $0,46 \mathrm{~g} / \mathrm{L} / \mathrm{h}$ [35].

Al emplearse durante un tratamiento de detoxificación básico una combinación de valores elevados de temperatura y $\mathrm{pH}$ se pueden remover una fracción de los azúcares reductores disminuyendo el rendimiento de celulosa del tratamiento y, por ende, el rendimiento global del proceso. Horváth y colaboradores [36], evaluaron el efecto de diferentes condiciones de overliming (temperatura y $\mathrm{pH}$ ) sobre un hidrolizado ácido de astillas de abeto rojo (Picea abies) y su posterior desempeño en una fermentación. El tiempo de duración del tratamiento de overliming fue de $3 \mathrm{~h}$; el rango de $\mathrm{pH}$ seleccionado fue de 8 a 12 y el de temperatura de 5 a $80^{\circ} \mathrm{C}$. De los ensayos realizados se logró concluir que una combinación de $\mathrm{pH} /$ temperatura igual o superior de $11 / 55^{\circ} \mathrm{C}$, remueve del 64 a $97 \%$, respecto a la concentración inicial de azúcares. Se debe resaltar que en este estudio solo se tuvo en cuenta la concentración de glucosa y manosa [36]. La selección errónea de las condiciones de $\mathrm{pH}$, temperatura y tiempo, que en el trabajo fue $12,60^{\circ} \mathrm{C}$ y 1 hora, pudo haber sido una de las causas por las cuales se presentó una pérdida del $27 \%$ de glucosa en el hidrolizado de Panicum maximum. El efecto de cada tratamiento de detoxificación no deja de ser particular dependiendo de la biomasa para obtener el hidrolizado, por lo tanto, es necesario estudiar las condiciones en cada sistema empleando como referencia con lo reportado en la literatura sin tomarlo como una verdad absoluta para el proceso.

En este trabajo, se empleó la técnica de análisis cromatográfico descrita por Mateus y colaboradores [37] para la cuantificación de hidroximetilfurfural (HMF) y furfural en el hidrolizado sin detoxificar y detoxificado, sin detectar ninguno de los dos compuestos, lo cual podría sugerir que la operación de detoxificación para este hidrolizado podría omitirse tomando como referencia estos dos compuestos inhibidores. Sin embargo, como se describe a continuación, en los ensayos de fermentación de observaron claras diferencias en el rendimiento de etanol. La fermentación de cada hidrolizado detoxificado se realizó sin ajustar la concentración inicial de glucosa con el objetivo de simular un proceso continuo de detoxificación y fermentación, de esta manera de logró eliminar parte de las perturbaciones en los ensayos. En la Figura 6 y Figura 7, se muestra el consumo de glucosa y producción de etanol y glicerol durante los ensayos de fermentación. Estos se realizaron por triplicado y en las gráficas se colocan los valores promedio de las concentraciones. Independientemente del tratamiento de detoxificación empleado sobre el hidrolizado, los tiempos de fermentación fueron inferiores a $24 \mathrm{~h}$. El valor coincide con lo reportado por Sharma y colaboradores [38] y Tewari y colaboradores [39] los cuales determinaron este tiempo como el óptimo para la producción de etanol de un hidrolizado ácido o enzimático de residuos agroindustriales y biomasa lignocelulósica empleando Saccharomyces cerevisiae. 


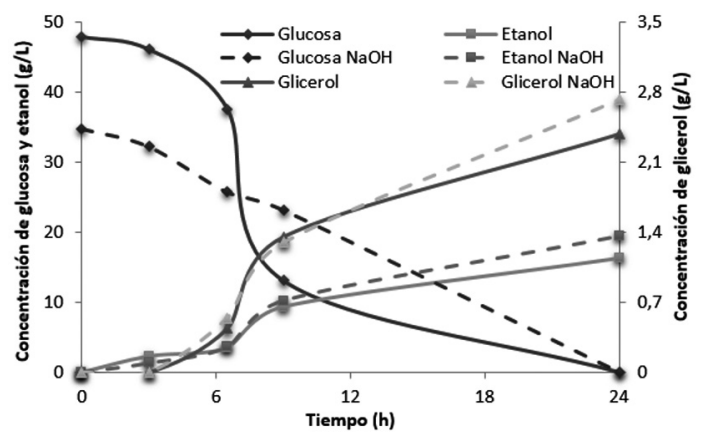

Figura 6. Consumo de glucosa, producción de etanol y glicerol durante la fermentación del hidrolizado sin detoxificar y detoxificado con hidróxido de sodio $(\mathrm{NaOH})$.

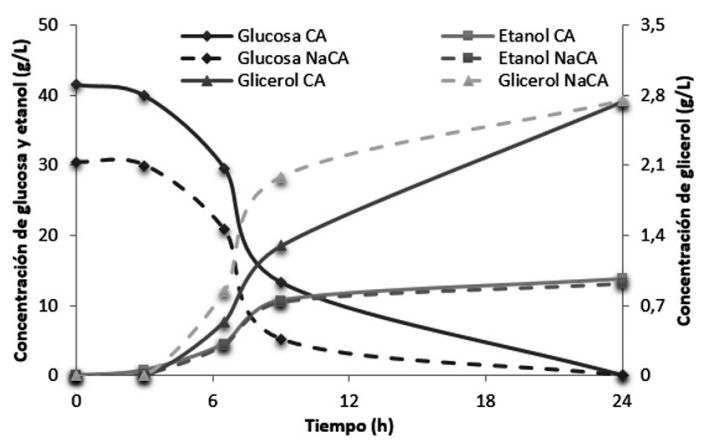

Figura 7. Consumo de glucosa, producción de etanol y glicerol durante la fermentación del hidrolizado detoxificado con carbón activado (CA) y detoxificado con CA + $\mathrm{NaOH}$

El hidrolizado detoxificado con la combinación de tratamientos, carbón activado e hidróxido de sodio, presento la tasa más alta de consumo de glucosa con $83 \%$ de sustrato consumido en 9 horas de fermentación. En el hidrolizado detoxificado con carbón activado y sin detoxificar el consumo fue de $68 \%$ y $73 \%$, respectivamente. Una tasa de consumo de glucosa tan elevada en un tiempo tan corto de fermentación reafirma lo mencionado anteriormente y reduce junto con costos de operación el riesgo de contaminación. El hidrolizado tratado con hidróxido de sodio, presento la tasa de consumo más baja con 33\% de consumo de sustrato en $9 \mathrm{~h}$ de fermentación.

En términos de rendimiento y productividad de etanol, la estrategia de detoxificación con hidróxido de sodio fue la más favorable para tratar el hidrolizado de $P$. maximum antes de la fermentación. Con esta estrategia y luego de una fermentación de $24 \mathrm{~h}$, se obtuvo 19,43 g/L de concentración de etanol con un rendimiento de $0,56 \mathrm{~g}$ etanol/g glucosa y una productividad de $0,81 \mathrm{~g} / \mathrm{L} / \mathrm{h}$. El rendimiento de etanol para esta fermentación fue superior al teórico, $0,51 \mathrm{~g}$ etanol $/ \mathrm{g}$ glucosa, este fenómeno se puede presentar por la fermentación de xilosa presente en el hidrolizado detoxificado por parte de la Saccharomyces cerevisiae, al existir evidencia de una ruta para el empleo de esta pentosa como sustrato para la producción de alcoholes [40]. La concentración de glicerol en todos los experimentos fue cercana a 2,5 g/L. Para las otras estrategias de detoxificación, los resultados se pueden observar en la Tabla 4.

Una forma de entender por qué la productividad de la fermentación fue tan alta, es debido al contenido de proteína del hidrolizado proveniente del P. maximum. Según Iljin [41], la especie de Panicum maximum empleada en este estudio podría presentar un contenido de proteína cruda total de 4,1\% - 13,4\%, donde la proteína cruda soluble correspondía a un $0,6 \%-1,8 \%$. En composición elemental el contenido de fosforo

Tabla 4. Concentración final y rendimiento de biomasa $\left(\mathrm{Y}_{\mathrm{X}}\right)$ y etanol $\left(\mathrm{Y}_{\mathrm{P}}\right)$, y productividad de etanol $(\eta)$ en una fermentación de hidrolizado de P. maximum

\begin{tabular}{|l|c|c|c|c|c|}
\hline \multicolumn{1}{|c|}{ Detoxificación } & $\begin{array}{c}\text { Biomasa } \\
(\mathbf{g} / \mathbf{L})\end{array}$ & $\begin{array}{c}\mathbf{Y}_{\mathbf{x}} \\
\left(\mathbf{g}_{\mathbf{x}} / \mathbf{g}_{\mathbf{s}}\right)\end{array}$ & $\begin{array}{c}\text { Etanol } \\
(\mathbf{g} / \mathbf{L})\end{array}$ & $\begin{array}{c}\mathbf{Y}_{\mathbf{p}} \mathbf{g}_{\mathbf{p}} / \\
\left.\mathbf{g}_{\mathbf{s}}\right)\end{array}$ & $\begin{array}{c}\eta^{*} \\
(\mathbf{g} / \mathbf{L} / \mathbf{h})\end{array}$ \\
\hline Sin detoxificar & 6,15 & 0,13 & 16,28 & 0,34 & 0,68 \\
\hline Hidróxido de sodio $(\mathrm{NaOH})$ & 7,88 & 0,23 & 19,43 & 0,56 & 0,81 \\
\hline Carbón activado $(\mathrm{CA})$ & 6,05 & 0,15 & 13,77 & 0,33 & 0,57 \\
\hline Combinación $\mathrm{NaOH}+\mathrm{CA}$ & 7,30 & 0,24 & 13,03 & 0,43 & 0,54 \\
\hline
\end{tabular}

*La productividad se determinó a las 24 h de fermentación. 
pudo variar entre $0,11 \%-0,44 \%$, calcio, $0,30 \%$ - $0,85 \%$, magnesio, $0,16 \%-0,35 \%$, y potasio, $0,85 \%-3,13 \%$. Estos valores se encuentran en porcentaje de biomasa seca.

Parte de la proteína soluble pudo liberarse durante el pretratamiento con ácido diluido de la biomasa junto con algunos de los elementos mencionados, y otra parte de los mismos se pudo haber recuperado en el hidrolizado [42]. Al no tener certeza de la cantidad recuperada, se realizó la suplementación de YNB (suplemento rico en aminoácidos) en el hidrolizado. Sin embargo, no se le debe restar importancia a la presencia de estas sustancias en el hidrolizado, debido a que cada una de ellas tiene una función específica sobre el buen desempeño de la levadura. Los aminoácidos contribuyen a la formación y buena funcionalidad de las enzimas. El fosforo interviene en la formación de ácidos nucleicos, transducción de energía y estructura transmembranal. El calcio es un segundo mensajero de la señal de transducción. Magnesio interviene en la actividad enzimática y formación de organelas celulares. El potasio juega un rol importante en el balance iónico de la célula [43]. Cabe resaltar, que no se realizó suplementación de una fuente de nitrógeno orgánico como extracto de levadura, extracto de malta o peptona.

Lu y colaboradores [22], encontraron que el lavado de la biomasa pretratada antes de dosificarla en una hidrólisis enzimática con alta concentración de sólidos es fundamental para evitar un descenso en el rendimiento de la fermentación. Al realizar ensayos de fermentación con hidrolizado enzimático de paja de trigo pretratada con explosión de vapor encontraron un descenso del $68 \%$ al $20 \%$ en rendimiento de etanol al emplear una biomasa pretratada lavada en comparación a una sin lavar. Gracias a la importancia del lavado, antes de la hidrólisis enzimática, toda biomasa pretratada con ácido sulfúrico diluido, recibió un lavado con agua destilada estéril, de manera que se lograran remover parte de los compuestos inhibidores de la fermentación como HMF y furfural (producto de la degradación de hemicelulosa durante el pretratamiento), antes que fuesen liberados durante la degradación de celulosa en la hidrólisis. Este argumento, justificaría por que no se pudo detectar estos inhibidores de fermentación en el hidrolizado de P. maximum.

\section{CONCLUSIONES}

La dosis recomendada para una hidrólisis enzimática de $P$. maximum pretratado bajo las condiciones seleccionadas en este trabajo fue de $61,44 \mathrm{BHU} / \mathrm{g}$ para el complejo de celulasas (NS22086) y 1,77 $\mathrm{CBU} / \mathrm{g}$ para $\beta$-glucosidasas (NS22118) con un rendimiento de conversión de celulosa a glucosa de $0,80 \mathrm{~g}$ celulosa/g biomasa pretratada seca, empleando una solución amortiguadora de citrato a pH 4,$8 ; 48$ h y $50^{\circ} \mathrm{C}$.

Con un sistema de lote alimentado (biomasa pretratada/enzimas) en una hidrólisis enzimática se logró alcanzar una concentración de biomasa pretratada de $20 \%$ p/p con una concentración final de azúcares reductores de $66,79 \mathrm{~g} / \mathrm{L}$ en un tiempo de $48 \mathrm{~h}$ con una productividad de $1,40 \mathrm{~g} / \mathrm{L} / \mathrm{h}$ y un rendimiento de conversión de celulosa a glucosa de $0,61 \mathrm{~g}$ celulosa/g biomasa pretratada seca.

A pesar de no haberse detectado inhibidores de fermentación (HMF y furfural) en el hidrolizado de $P$. maximum y reducir en $27 \%$ la concentración inicial de glucosa, el hidrolizado detoxificado con hidróxido de sodio fue el de mayor concentración de etanol y productividad, con 19,43 g/L y $0.81 \mathrm{~g} / \mathrm{L} / \mathrm{h}$, en $24 \mathrm{~h}$ de fermentación.

\section{AGRADECIMIENTOS}

C.R. Castillo-Saldarriaga agradece el apoyo al Departamento Administrativo de Ciencia, Tecnología e Innovación (Colciencias) por el financiamiento a través del Programa de Jóvenes Investigadores y a la beca de posgrado de la Fundación Juan Pablo Gutiérrez Cáceres.

\section{REFERENCIAS}

[1] H. Al-Maamary, H. Kazem and M. Chaichan. "The impact of oil price fluctuations on common renewable energies in GCC countries". Renewable and Sustainable Energy Reviews. Vol. 75, pp. 989-1007. August 2017. ISSN: 1364-0321. DOI: 10.1016/j.rser.2016.11.079.

[2] A. Lavaller. "Low oil price impact on Latin American non-conventionals". Geopolitics of Energy. Vol. $38 \mathrm{~N}^{\circ}$ 3. January 2016. ISSN: 0273-1371. 
[3] C. Hong-Zhang and L. Zhi-Hua. "Enzymatic hydrolysis of lignocellulosic biomass from low to high solids loading”. Engineering in Life Science. Vol. 00, pp. 1-11. October 2016. ISSN: 1618-2863. DOI: 10.1002/ elsc. 201600102.

[4] F. Ruiz, E. Rodríguez, J. Pinzón, H. Anzola y L. Castro. "Establecimiento y evaluación del guinea Panicum maximum cv. Massai en la hacienda Guachicono del Bordo, Patía (Cauca)". Revista Ciencia Animal. Vol. 9, pp. 125-154. Marzo 2015. ISSN: 2011-513X.

[5] J.Larsen, M. Ostergaard, L. Thirup and H. Wen. F. Krogh. "The IBUS process - Lignocellulosic bioethanol close to a commercial reality". Chemical Engineering \& Technology. Vol. 31 $\mathrm{N}^{\circ}$ 5, pp. 765-772. April 2008. ISSN: 15214125. DOI: $10.1002 /$ ceat.200800048.

[6] Y. Bin, Z. Dai. S. Ding and C. Wyman. "Enzymatic hydrolysis of cellulosic biomass". Biofuels. Vol. $2 \mathrm{~N}^{\circ}$ 4, pp. 421-450. ISSN: 1759-7269. DOI: 10.4155/BFS.11.116.

[7] Y. Sugiharto, A. Harimawan, M. Kresnowati, R. Purwadi, R. Mariyana, H. Fitriana and H. Hosen. "Enzyme feeding strategies for better fed-batch enzymatic hydrolysis of empty fruit bunch". Bioresource Technology. Vol. 207, pp. 175-179. May 2016. ISSN: 0960-8524. DOI: 10.1016/j.biortech.2016.01.113.

[8] D. Nieves, H. Ruiz, L. Cárdenas, G. Alvarez, C. Aguilar, A. Llyina and J. Hernández. "Enzymatic hydrolysis of chemically pretreated mango stem bark residues at high solid loading". Industrial Crops and Products. Vol. 83, pp. 500-508. May 2016. ISSN: 09266690. DOI: 10.1016/j.indcrop.2015.12.079.

[9] L. Ramos, L. Silva, A. Ballem, A. Pitarelo, L. Chiarello and M. Silveira. "Enzymatic hydrolysis of steam-exploded sugarcane bagasse using high total solids and low enzyme loadings". Bioresource Technology. Vol. 175, pp. 195-202. January 2015. ISSN: 0960-8524. DOI: 10.1016/j.biortech.2014.10.087.

[10] J. Yang, X. Zhang, Q. Yong and S. Yu. "Threestage enzymatic hydrolysis of steam-exploded corn stover at high substrate concentration". Bioresource Technology. Vol. $102 \mathrm{~N}^{\circ}$ 7. April, 2011. ISSN: 0960-8524 DOI: 10.1016/j. biortech.2010.12.047.

[11] D. Hodge, M. Karim, D. Schell and J. McMillan. "Model-based fed-batch for high-solids enzymatic cellulose hydrolysis". Applied Biochemistry and Biotechnology. Vol. 152, pp. 88-107. May 2008. ISSN: 02732289. DOI: $10.1007 / \mathrm{s} 12010-008-8217-0$.

[12] Y. Yang and C. Lew. "Detoxification of hemicellulose-rich poplar hydrolysate by polymeric resins for improved ethanol fermentability". Fuel. Vol. 203, pp. 187-196. September 2017. ISSN: 0016-2361. DOI: 10.1016/j.fuel.2017.04.118.

[13] E. Palmqvist and B. Hagerdal. "Fermentation of lignocellulosic hydrolysates. I: inhibition and detoxification". Bioresource Technology. Vol. $74 \mathrm{~N}^{\circ} 1$, pp. 17-24. August 2000. ISSN: 0960-8524. DOI: 10.1016/ S0960-8524(99)00160-1.

[14] Frederick, N. Zhang, N. Djioleu, A. Ge X. $\mathrm{Xu}$, J. Carrier and D. Chapter 5 - The effect of washing dilute acid pretreated poplar biomass on ethanol yields. Sustainable degradation of lignocellulosic biomass - techniques, applications and commercialization. pp. 105117. May 2013. Editorial: INTECH. ISBN: 978-953-51-1119-1. DOI: 10.5772/56129.

[15] K. Rajan and K. Carrier. Effect of dilute acid pretreatment conditions and washing on the production of inhibitors and on recovery of sugars during wheat straw enzymatic hydrolysis. Biomass \& Bioenergy. Vol. 62, pp. 222-227. March 2014. ISSN: 0961-9534. DOI: 10.1016/j.biombioe.2014.01.013.

[16] C. Castillo-Saldarriaga. "Obtención de un hidrolizado detoxificado a partir de biomasa lignocelulósica de Panicum maximum para su uso como sustrato en la fermentación alcohólica". Tesis de Maestría en Ingeniería Ingeniería Química. 2014. Universidad Nacional de Colombia, Sede Bogotá. Bogotá, Colombia.

[17] A.D. Sluiter, B.R. Hames, R.O. Ruiz, C. Scarlata, J.B. Sluiter, D.W. Templeton and D. Crocker. "Determination of structural carbohydrates and lignin in biomass: laboratory analytical procedure (LAP)". NREL/TP-510-42618. National Renewable Energy Laboratory. Golden. CO, USA.

[18] T. Ghose. "Measurement of cellulose activities". Pure and Applied Chemistry. Vol. $59 \mathrm{~N}^{\circ}$ 2, pp. 257-268. January 1987. ISSN: 0033-4545. DOI: 10.1351/ pac198759020257. 
[19] A. Saqib and P. Whitney. "Differential behavior of the dinitrosalicylic acid (DNS) reagent towards mono- and di-saccharide sugars". Biomass and Bioenergy. Vol. $35 \mathrm{~N}^{\mathrm{o}} 11$, pp. 4748-4750. November 2011. ISSN: 09619534. DOI: 10.1016/j.biombioe.2011.09.013.

[20] W. Xiao, W. Yin, S. Xia and P. Ma. "The study factors affecting the enzymatic hydrolysis of cellulose after ionic liquid pretreatment". Carbohydrate Polymers. Vol. $87 \mathrm{~N}^{\circ} 3$. pp. 2019-2023. February 2012. ISSN: 01448617. DOI: 10.1016/j.carbpol.2011.10.012.

[21] I. Wood, A. Elliston, P. Ryden, I. Bancroft, I. Roberts and K. Waldron. "Rapid quantification of reducing sugars in biomass hydrolysates: improving the speed and precision of the dinitrosalicylic acid assay". Biomass and Bioenergy. Vol. 44, pp. 117-121. September 2012. ISSN: 0961-9534. DOI: 10.1016/j. biombioe.2012.05.003

[22] Y. Lu, Y. Wang, G. Xu, J. Chu, Y. Zhuang and S. Zhang. "Influence of high solid concentration on enzymatic hydrolysis and fermentation of steam-exploded corn stover biomass". Applied Biochemistry and Biotechnology. Vol. $160 \mathrm{~N}^{\circ}$ 2. pp. 360369. January 2010. ISSN: 0273-2289. DOI: 10.1007/s12010-008-8306-0.

[23] S. Rabelo. "Evaluation and optimization of pretreatments and enzymatic hydrolysis of the sugarcane bagasse for second generation ethanol production". Doctorate Thesis. 2010. The University of Campinas. Campinas, Brazil.

[24] M. Yang, W. Li, B. Liu, Q. Li and J. Xing. "High concentration sugars production from corn stover based on combined pretreatments and fed-batch process". Bioresource Technology. Vol. $101 \mathrm{~N}^{\circ} 13$. pp. 4884-4888. July 2010. ISSN: 0960-8524. DOI: 10.1016/j.biortech.2009.12.013.

[25] X. Zhao, L. Dong, L. Chen and D. Liu. "Batch and multi-step fed-batch enzymatic saccharification of Formiline-pretreated sugarcane bagasse at high solid loading for high sugar and ethanol titers". Bioresource Technology. Vol. 135, pp. 350-356. May 2013. ISSN: 0960-8524. DOI: 10.1016/j. biortech.2012.09.074.

[26] D. Hodge, C. Andersson, K. Berglund and U. Rova. "Detoxification requirements for bioconversion of softwood dilute acid hydrolysates to succinic acid". Enzyme and Microbial Technology. Vol. $44 \mathrm{~N}^{\circ} 5$, pp. 309-316. May 2009. ISSN: 0141-0229. DOI: 10.1016/j.enzmictec.2008.11.007.

[27] R. Millati, C. Niklasson and M. Taherzadeh. "Effect of $\mathrm{pH}$, time and temperature of overliming on detoxification of diluteacid hydrolysates for fermentation by Saccharomyces cerevisae". Process Biochemistry. Vol. $38 \mathrm{~N}^{\circ} 4$, pp. 515-522. December 2002. ISSN: 1359-5113. DOI: 10.1016/S0032-9592(02)00176-0.

[28] H. Miyafuji, H. Danner, M. Neureiter, C. Thomasser, J. Bvochora, O. Szolar and R. Braun. "Detoxification of Wood hydrolysates with Wood charcoal for increasing the fermentability of hydrolysates". Enzyme and Microbial Technology. Vol. $32 \mathrm{~N}^{\mathrm{o}}$ 3-4, pp. 396-400. March 2003. ISSN: 0141-0229. DOI: 10.1016/S0141-0229(02)00308-3.

[29] R. Rodrigues, M. Felipe, J. Almeida e Silva and P. Gómez. "The influence of $\mathrm{pH}$, temperature and hydrolyzate concentration on the removal of volatile and nonvolatile compounds from sugarcane bagasse hemicellulosic hydrolyzate treated with activated charcoal before or after vacuum evaporation". Brazilian Journal of Chemical Engineering. Vol. $18 \mathrm{~N}^{\circ}$ 3, pp. 299311. September 2001. ISSN: 0104-6632. DOI: 10.1590/S0104-66322001000300009.

[30] G. Banerjee, S. Car, T. Liu, D. Williams, S. Meza, J. Walton and D. Hodge. "Scale-up and integration of alkaline hydrogen peroxide pretreatment, enzymatic hydrolysis and ethanolic fermentation". Biotechnology and Bioengineering. Vol. $109 \mathrm{~N}^{\circ}$ 4, pp. 922-931. April 2012. ISSN: 1097-0290. DOI: 10.1002/ bit.24385.

[31] S. Ferreira, A. Duarte, M. Ribeiro, J. Queiroz and F. Domingues. "Response surface optimization of enzymatic hydrolysis of Cistu ladanifer and Cytisus striatus for bioethanol production". Biochemical Engineering Journal. Vol. $45 \mathrm{~N}^{\circ} 3$, pp. 192-200. August 2009. ISSN: 1369-703X. DOI: 10.1016/j. bej.2009.03.012.

[32] V. Pallapolu, Y. Lee, R. Garlock, V. Balan, B. Dale, Y. Kim, N. Mosier, M. Falls, M. Holtzapple, R. Sierra-Ramirez, J. Shi. M. Ebrik, T. Redmond, B. Yang, C. Wyman, B. Donohoe, T. Vinzant, R. Elander, B. 
Hames, S. Thomas and R. Warner. "Effects of enzyme loading and $\beta$-glucosidase supplementation on enzymatic hydrolysis of switchgrass processed by leading pretreatment technologies". Bioresource Technology. Vol. $102 \mathrm{~N}^{\circ}$ 24, pp. 11115-11120. December 2011. ISSN: 0960-8524. DOI: 10.1016/j. biortech.2011.03.085.

[33] R. Kumar and C. Wyman. "Access of cellulase to cellulose and lignin for poplar solids produced by leading pretreatment technologies". Biotechnology Progress. Vol. $25 \mathrm{~N}^{\mathrm{o}} 3$, pp. 807-819. August 2008. ISSN: 1520-6033. DOI: 10.1021/bp. 153 .

[34] A.Hassan. "Conversion of lignocellulosic material into fermentable sugars". Doctorate Thesis. 2012. Technical University of Berlin. Berlín, Alemania.

[35] S. Larsson, A. Reimann, N. Nilvebrant and L. Jonsson. "Comparison of different methods for the detoxification of lignocellulose hydrolysates of spruce". Applied Biochemistry and Biotechnology. Vol. 77-79, pp. 91103. ISSN: 0273-2289. DOI: 10.1385/ ABAB:77:1-3:91.

[36] I. Horvath, A. Sjode, B. Alriksson, L. Jonsson and N. Nilvebrant. "Critical conditions for improved fermentability during overliming of acid hydrolysates from spruce". Applied Biochemistry and Biotechnology. Vol. 124 NNo $^{\circ} 1-3$, pp. 10311044. March 2005. ISSN: 0273-2289. DOI: 10.1385/ABAB:124:1-3:1031.

[37] L. Mateus, O. Hernández, M. Velásquez and J. Díaz. "Dilute sulfuric acid pretreatment of goliath grass (Pennisetum glaucum $x$ Pennisetum purpureum) for ethanol cellulosic".
Revista Colombiana de Biotecnología. Vol. XIV No 1 , pp. 146-156. Julio 2012. ISSN: 0123-3475. ISSNe: 1909-8758.

[38] S. Sharma, K. Karla and G. Kocher. "Fermentation of enzymatic hydrolysate of sunflower hulls for ethanol production and its scale-up". Biomass \& Bioenergy. Vol. 27 $\mathrm{N}^{\circ}$ 4, pp. 399-402. October 2004. ISSN: 09619534. DOI: 10.1016/j.biombioe.2004.03.005.

[39] H. Tewari, S. Marwaha, J. Kennedy and L. Singh. "Acid and enzymatic saccharification of agricultural mixed polymers for alcohol production". British Polymer Journal. Vol. 19 $\mathrm{N}^{\circ}$ 5, pp. 425-428. September 1987. ISSN: 1097-0126. DOI: 10.1002/pi.4980190501.

[40] C. Batt, S. Carvallo, D. Easson, M. Akedo and A. Sinskey. "Direct evidence for xylose metabolic pathway in Saccharomyces cerevisiae". Biotechnology and Bioengineering. Vol. 28 $\mathrm{N}^{\circ}$ 4, pp. 549-553. April 1986. ISSN: $1097-$ 0290. DOI: 10.1002/bit.260280411.

[41] W, Iljin. "Relación entre suelo y composición química de las plantas forrajeras". Agronomía Tropical. Vol. 4, pp. 193-213. ISSN: 0002-192X.

[42] B. Quevedo-Hidalgo, F. Monsalve-Marín, P. Narváez-Rincón, A. Pedroza-Rodríguez and M. Velásquez-Lozano. "Ethanol production by Saccharomyces cerevisiae using lignocellulosic hydrolysates from Chrysanthemum waste degradation". World Journal of Microbiology and Biotechnology. Vol. $29 \mathrm{~N}^{\circ} 3$, pp. 459-466. March 2013. ISSN: 0959-3993. DOI: $10.1007 /$ s11274-012-1199-7.

[43] G. Walker. Chapter 3: Yeast nutrition. "Yeast Physiology and Biotechnology". John Wiley \& Sons, Inc. New York. New York, Estados Unidos. 1998. ISBN: 978-0-471-96446.9. 